\title{
DIGITALIZATION AND ITS IMPACT ON THE NATIONAL LABOUR MARKET AND EDUCATION SYSTEM. RESULTS OF A MODERATED DISCUSSION
}

\author{
Piotr HETMAŃCZYK \\ Central Mining Institute, Katowice; phetmanczyk@gig.eu, ORCID: 0000- 0001-8816-6037
}

\begin{abstract}
Purpose: The main purpose of the article is to justify the need for interdisciplinary professional training of employees for challenges related to the growing importance of dynamically developing digitalization, which is closely related to the development of civilization.

Design/methodology/approach: The theses presented in the article have been verified using: literature review, critical literature analysis, document research and comparative analysis.

Findings: Based on the content of this article, a future emerges in which man, industry and the surrounding reality will be shaped by digitalization developing with hitherto unknown dynamics. This phenomenon may lead to disappearance of world characteristic for industrial age and the transition to a new era determined by technologies based on data flow and its analysis. In digitalized economies, knowledge that is exemplified by a knowledge society that creates innovative solutions has become a key capital resource. It seems that digitalization in the context of economies' competitiveness will determine the need to raise the level of education and competences and to create and control new knowledge.

Originality/value: The article enriches knowledge and develops a discussion in the area of dynamically developing digitalization. Thanks to the knowledge presented in the article, it can be concluded that the decisive role in creating the development of a labour market and education can be overcome by breaking social and professional barriers to digitalization processes - which may favour the social dimension of individuals and strengthen the sense of fullness in human life $^{1}$.
\end{abstract}

Keywords: digitalization, labour market, education, survey.

Category of the paper: Conceptual paper.

\footnotetext{
${ }^{1}$ The article is the result of research carried out by the Central Mining Institute on behalf of the "KADRA" Trade Union Agreement and Trade Union Forum as part of the project entitled "A competent trade unionist - how to support employees in labour change processes", co-financed by the European Social Fund under the Operational Programme Knowledge Education Development 2014-2020.
} 


\section{Introduction}

The main objective of qualitative field research conducted among representatives of national trade union organisations was to determine the impact of digitalization on the Polish labour market and education system at every level of education ${ }^{2}$. The basis for the development of detailed research objectives was a quantitative analysis (desk research) diagnosing the impact of digitalization on the labour market and education in selected aspects - at the same time enabling appropriate targeting of research, determining its scope and experts included in it. In this context, it should be noted that qualitative research serves the following specific research objectives: 1) An initial determination of the state of knowledge by the surveyed experts on digitalization. In turn, the specific objectives are aimed at obtaining expert opinions on the phenomenon under study and its diversity in the context of impact on the national labour market and education system at every level of education. 2) Obtaining the opinions of experts concerning changes noticed in their environment determined by digitalization - problems arising in enterprises and the industry in which experts operate and the ways to solve them. 3) Diagnosing opinions on the positive and negative effects of digitalization along with defining its development directions - and in terms of their impact on the labour market and education. The results obtained from the research were used to determine if the analysed process threatens the development of the labour market and education system at every level of education. On the other hand, the opinions of experts concerning digitalization allowed for the creation of in-depth conclusions for changing processes on the labour market and education system.

\section{Characteristic of the FGI moderated discussion}

A focus group interview (FGI) is a qualitative research technique, which has a rather long history in social sciences (dating back to the thirties of the 20th century) and an extensive theoretical background. It can be used both as an independent research technique (primarily in marketing research when it comes to gathering opinions on a given product or generating new solutions), as well as in combination with other quantitative and qualitative techniques at various stages of the research process (as an exploratory technique that allows for an initial understanding of a research problem or a technique to deepen the understanding of previously collected data). The priority of group interviews is to allow each respondent to speak freely. This could be difficult if there are too many people. It is equally important that the group does not split, which is difficult to avoid with too many people taking part in the interview.

\footnotetext{
${ }^{2}$ The orderer defined cognitive area (digitalization) implementing research and identified experts to the research. The moderated group discussion took place on 26 June 2019 in Katowice.
} 
Ultimately, the number of people involved is determined by research on the problem structure, significant respondent characteristics, technical conditions (e.g. maximum interview duration, venue organisation) and interviewer preferences. The FGI allows the researcher to use group dynamics. It differs from an individual interview (IDI), which is conducted with each individual respondent separately. The interaction between the subjects themselves is crucial for the focus, and the conversation takes place in a wider social context. It is assumed that the respondents do not always have a definite opinion on the topics covered. On the other hand, opinions are largely shaped in the context of views expressed by other people. Focus interviews are therefore closer to real social life situations, which largely avoid the artificiality to which other techniques used in social sciences are exposed.

Participation in a focused group interview is a social situation that allows one to activate deeper emotional layers. The statements of respondents participating in the focus also tend to be more understandable, since it is possible to relate the statements to the context in which they appear. When designing, conducting and analysing focus results, it is necessary to have knowledge in the field of social psychology (issues of social behaviour) and microsociology (small social group dynamics). For this reason, focused group interviews require the person who moderates them to have a high level of competence. The selection of a suitably qualified moderator is one of the most important factors influencing the quality of collected research material. The role of the moderator is to conduct discussions focused on the problem, not to ask questions (polled respondents). It is important for the moderator to be able to involve less active people in the conversation and not allow the emergence of a spontaneous leader who will take over the role of the interviewer. Many means serve this, such as verbal and non-verbal behaviour. Focus group interviews - like any other research technique - have some limitations. First of all, the collected data does not allow for the generalisation of results for an entire population (for this purpose - as a complement to focus - it is possible to use quantitative techniques). In addition, the analysis of the results - although always theoretically founded is exposed to a certain degree of subjectivity on the part of the researcher, which should also be taken into account.

The choice of an FGI moderated discussion for the research was dictated by the specificity of the research problem. Data gathered through focus interviews allows for a more in-depth analysis than quantitative techniques. Focuses also have an advantage over individual interviews, because they permit more varied results. By conducting a focus, it is possible to gather a wide spectrum of data (in this study: motivations, attitudes, barriers to participation in megatrends).

The use of qualitative techniques - which include FGI interviews - allows one to obtain a reliable description of the phenomena studied (answer to the question: "what?"), learn the mechanisms of action (answer to the question: "how?") and - what is particularly important understand causal conditions (answer to the questions: "why?", "for what?"). A qualitative analysis is not used to quantify data (questions: "how much?", "what percentage?"). This is not 
a defect of the focus, because the purpose of a qualitative analysis is to understand social reality, not to measure phenomena. FGI - thanks to its recording is used to provide a comprehensive analysis of the material, not only the statements of the respondents, as well as other behaviours (position in the group, readiness to defend their opinion, the level of conformity, etc.).

The use of FGI is particularly justified in the research, because, in this case, we are dealing with a group of experts. Discussions in expert environments very often generate new solutions and allow one to perceive otherwise elusive aspects of the problem under consideration. FGIs consist not only in expressing opinions, but also in generating new ideas: in some contexts, they are similar to the activities of creative groups. Therefore, it seem to be a much more effective technique than collecting isolated respondent statements (IDI interviews).

\section{Digitalization according to discussion group}

The interview analysed in the report took place on 26 June 2019 and lasted two hours. Twenty-one respondents participated, invited according to agreed criteria with the orderer. The priority was to invite representatives of trade union organisations from industries closely related to the issue to participate in each meeting.

The focus study consisted of a joint discussion with a group of respondents on a given topic. During the group interview, research questions were asked to explain or understand the phenomenon of digitalization, as well as the attitudes and behaviour of assembled respondents. The participants in the discussion stimulated each other, inspiring and provoking one another to express their opinions and construct ideas.

The study was conducted by a moderator who supervised the discussion and directed the conversation in accordance with the planned scenario. The course of the group discussion was recorded on audio media, and the basis for the interpretation of the results was an in-depth analysis of the interview conducted by the researcher. The trade union environment repressented by respondents recruited for focus group interviews - is very diverse. On the one hand, there are people with many years of professional experience among them; on the other hand, there are those who are just starting their cooperation with unions. There are many dimensions that differentiate the environment of trade unions in the subject of digitalisation, and they will be discussed in detail in the following analysis.

Almost all respondents agree that digitalisation is already occurring and cannot be stopped. This applies to both young people (they cannot communicate with the environment other than via messengers) and older people (older people are digitally excluded). Young people approach modern devices in an intuitive way (digital devices accompany young people from the moment of their birth, they are not afraid of new products) and natural (they use communication applications, I use GPS for orientation in the field). Elderly people need more time to become 
familiar with technology (an older person needs to spend more time acquiring knowledge), but they also often enjoy technological development (going to the office, you also need to have knowledge about digital news, because without it nothing we can do). According to the respondents, the digitalization process is an act that allows them to save time: comparing it with the time before digitalization, it saves more time-you do not have to get to their headquarters, wait in line, etc. This hedonistic aspect of digitalization is a motivation confirming that it is impossible to stop the technological development process associated with almost every activity. The respondents themselves consider digital development as valuable, and they require only training. One respondent even stated that it is necessary to constantly transfer knowledge about new technologies and equipment.

As the respondents emphasise, the digitalization process significantly affects the development of the economy. It is known that the economies of individual regions are different and should not be compared (We should focus on our own continent and not compare ourselves with America or Asia). It needs to focus on the nearest countries or regions (the digitalization of the economy in Germany or the Czech Republic is greater than in Poland). As the digitalization of the economy progresses, respondents report increasing productivity (productivity in Germany is greater than in Poland despite digitalization) and cost reduction (digitalization reduces costs), which can also contribute to employment reduction (digitalization can also be combined with less employment). All participants agree that it is impossible to stop the present process or even get back to a period before digitalization (you cannot go back to the period before the start of digitalization). It is necessary to become familiar with all the technological novelties so as not to have problems in the future (digitalisation is inevitable, and we have to follow the world so as not to be left behind, you have to learn how to use these things).

There are numerous voices among the respondents which emphasise that digitalization despite its many qualities - can also contribute to negative phenomena. This applies to the above-mentioned employment reduction or if there is a malfunction of the power system or an application. One of the respondents said: a non-functioning application is already causing a problem when I cannot withdraw money or to settle matters at the office. The idea of fearing failure exceptionally summarises the following statement: if there is no electricity - a blackout - we will not be able to do anything; Internet off, no payment available, mobile phones will not work as most landline ones. Moreover, there are indicated areas no longer used due to their substitution by digital counterparts (young people are not able to use old equipment such as maps. However, it was adults who allowed it, not digitalization. Because we cannot adjust tools so that students can use them).

The positive feelings generated in the process of digitalization - saving time, increasing productivity - are conditioned by many factors. Among them, the issue of providing appropriate remuneration comes to the fore. The salary in everyone's life undoubtedly provides a basis for one's existence. One respondent describes it as follows: digitalization is aimed at increasing 
work efficiency. There will be a person in the workplace, but he will have to be better paid. We will talk about the cost of this service, product. There will always be a demand for an employee. This statement is, among others, so interesting, because it addresses the issue of the need for an employee, despite the gradual replacement of jobs by artificial intelligence. Importantly, our economy is based on branches that are very vulnerable to benefits resulting from the implementation of artificial intelligence (Założenia..., 2018). The Polish economy is increasingly gathering data, but it is still poorly analysing it, so a person will be needed who will develop this database, enter the data and complete it. It is comforting that young people easily absorb modern solutions and strive to increase knowledge in this area - which is noticeable in the respondents' opinion - We are currently not prepared for digitalization, because the process itself is at an early stage. We need to find people who will be able to use these new solutions.

Progress in recent years is noticeable. The Polish economy is growing steadily in the world rankings, which is noticeable in the statement of one respondent: we are only slightly lagging behind in comparison to Western Europe, but we are afraid of change. However, companies that negate or delay the implementation of digitalization, including AI, will begin to lose their competitive advantage over the next few years. Importantly, this applies not only to industries traditionally associated with data - banks, insurers, trading, marketing - but also for those that are less digitised, such as as industry or agriculture (Założenia..., 2018). It is worth noting that the digitalization of the economy is introduced with a view to enhancing human security and not be afraid of jobs loss, because in place of the liquidated jobs will be created new ones (Gartner, 2017).

The European Union provides support to be able to adjust to labour market changes taking place in the world, including digital changes. One of the supports it is social affairs pillar, which include working conditions (European Commission, 2017). Working conditions, including salary, are important element of employment for respondents: despite the digitalization of man will be needed in the workplace, but he will have to be better paid, we cannot only generate low-paid work. Appropriate minimum wages should be ensured so that the needs of the employee and his family are met in light of national economic and social conditions, while also ensuring access to employment and the motivation to look for a job.

The respondents believe that fair remuneration stop educated workers in the country. The pay dimension must be adequate to the type and amount of work, as well as to its quality and the qualifications necessary to perform it.

The desire to preserve and strengthen the European social model is noticed by most experts. But in order to keep it, it necessary to meet the new challenges posed by a globalised world. One respondent noted that: since joining the European Union, Poland has gained a lot. The respondents believe that participation in training financed by the Union is no longer sufficient for competitiveness on labour market, which is perfectly illustrated by the following statement: the training must carry something behind, not only to indicate that the training had 
to take place and it came to this. It is important to develop a plan whereby the Polish economy will be able to compete with the world economy in the era of digitalization.

People struggling with job loss or facing change need comprehensive support based on improving qualifications and retraining, access to employment services and social services throughout their professional careers. The issue of training is central in debates concerning a digital economy. One of the ways to help those situated in difficulty is training. The respondent notes that training to increase professional competence is frequently offered to men, which is incompatible with the principle of equal opportunity for men and women, which focuses on the same social value, equal rights and obligations and - what is important at this point - equal access to social resources (including public services, labour market) (Piotrowska et al., 2016). Therefore, efforts should be made in which both women and men have conditions created for their development, both in personal and professional areas, and making such life choices that result from their personal needs, aspirations and talents. This aspect was also widely discussed by the respondents. They believe that the employee will know what training is interesting for him and which will be good for his professional development. It is worth emphasising at this point that the economic factor of participation in training is also quite important. One respondent explicitly stated that the first training must be present, because it affects the financial situation of the company, and the possibility of sending an employee for training will depend on this situation. Therefore, we should strive to change the way to aid the worker or the company in which the employee is employed. This means financing companies so that they can send staff for training. This should take into account the opinion of experts that in order to function properly on the labour market, one should take part in training that are needed, because the trends are changing, and there are new solutions.

The desire to make the best use of the EU's long-term budget for 2021-2027 is noticed by most experts. This should primarily concern the financing of future skill policies and the measures to support changes in the labour market in the age of digitalization. One of the respondents believes that there is a lack of a proper debate about the digitalization process in Poland. The activities carried out in the area of national policy are considered to be correct. According to the most of respondents should change the assessment of the main policy tool of skills, which is training. The respondents also showed interest in the question of who will decide about these trainings? In the opinion of experts, a statement that repeatedly appears is participation in important development training causes the employee to develop. Therefore, according to these opinions, it is the employee who should submit the training offer to which the employer would consent.

Another topic raised by experts was for ensuring an active labour market policy in the age of digitalization. But to be effective, as the respondents note, proper knowledge of people working in employment services is necessary. Most of the electronic public services currently operating at both a local and central level are used only occasionally. This is often due to many overlapping causes, among which are: high complexity of e-services, inability to settle the 
whole matter electronically, lack of knowledge about the possibility of settlement services by Internet and the lack of real benefits of using e-services. An important highlight is the fact that part of the problems for officials whom provide services in an electronic form are usually caused by a competence gap, as well as by vague regulations that make it difficult and sometimes even impossible to replace paper documents with a digital form (Strategia rozwoju..., 2016).

As experts stress, economic development brings benefits which should reach all Europeans, including Poles. As one respondent notes, the digitalization process is not yet very advanced, but it cannot be stopped. To ensure greater safety at work, it should seek investors from the innovation industry (Czerwiński, 2019). Therefore, it should be recognised that technological and digital development will help Poland and Polish entrepreneurs find themselves in the favoured area of the world's largest economies. The German media already indicates that Poland's digital development has outperformed Germany, where non-cash payments, highspeed Internet and ease of starting a business are commonplace.

Experts believe that training is an important tool for professional development; however, to be effective, it should be conducted by a person with proper knowledge and the ability to transfer it.

The respondents also indicated that future prosperity will depend heavily on how well societies and governments cope with the digital revolution and that modern and future-oriented learning is necessary to find a new reality.

\section{Conclusions and recommendations}

This paper seeks to show the perception of digitalization in the present and future world. Digital transformation is a significant challenge for the labour market and education. The development of an information society, which is a new phase in the development of societies, is a challenge and is an important element in creating a modern economy based on innovation and advanced technologies, in which intellectual capital is the most important (Głąb, 2016).

Based on literature research and a moderated discussion with a focus group on the digitalization process, can be formulate the following recommendations for the organisation in utilitarian part of the study and social dialogue institutions - in particular trade unions - aimed at strengthening their knowledge and position in a conscious public debate on the effects of a country's economic transformation and its social effects (Hetmańczyk, 2019). 
- Due to lack of studies indicating the impact of digitalization on the Polish labour market, research in this area should be carried out.

- It is worth considering taking actions that affect the development of training forms, allowing older people to acquire knowledge about using new technological solutions.

- It seems important to develop the concept of establishing a "transformation fund" allowing companies to obtain grants for research and training in the field of digitalization and purchase of new technological solutions.

- It is necessary to implement a unified training effectiveness assessment system, which, in conjunction with the results, will create an adequate training programme for employees (trade unionists), which in turn allows trainers to lead the trained group towards precisely defined goals. Setting goals and training results is key to developing a training programme, choosing forms and methods and, later, reliable assessment of the effectiveness of the entire training process.

- People struggling with job loss or facing a change in situation need comprehensive support based on upgrading their qualifications and retraining. Therefore, it is postulated to introduce to the training a programme to increase the digital competence of the employee (trade unionist). It is worth applying competency tests before and after training.

In the context of digitalization analysed in the above text, it is extremely interesting to anticipate the process of growth and development of a digital society. In this society there are a class of digital employees who can work anywhere and create numerous personal and business digital contacts. In this way, this class determines the process in which digital knowledge becomes the foundation of the power of the global economy. In such a shaped world, digital creativity and curiosity prevail, which are the main characteristics of young people. The need to exchange knowledge between young people and the older generation is clearly emerging in this process. The indicated relationship is aimed at the urgent need to reduce the growing intergenerational information gap. It seems that only communities in which this gap will not take place will be able to create new technologies and solutions in a world based on digital knowledge. An important aspect in this regard is the maintenance of traditional forms of contact. Everything cannot be based solely on virtual communication. It is important to preserve traditional forms of intergenerational cooperation based on joint decision making, motivation to cooperate, loyalty and honesty. In this context, it seems that in an increasingly digitised world supporting intergenerational integrity and openness prevails over digital wisdom. 


\section{References}

1. Czerwiński, A. (2019). Raport 15 lat w Unii Europejskiej. Warszawa: Polski Instytut Ekonomiczny.

2. European Commission (2017). White paper concerning European future, COM(2017) 2025, Brussels.

3. Gartner (2017). https://www.gartner.com/en/newsroom/press-releases/2017-12-13-gartnersays-by-2020-artificial-intelligence-will-create-more-jobs-than-it-eliminates, 25.07.2019.

4. Gazeta.pl (2019). http://next.gazeta.pl/next/1,151003,24996171,niemiecka-prasa-siliconwarszawa-polska-dystansuje-niemcy.html\#s=BoxOpImg1, 16.07.2019.

5. Głąb, K. (2016). Kompetencje przyszłości w cyfrowej dysrupcji. Warszawa: Fundacja Naukowa Evidence Institute.

6. Hetmańczyk, P. (2019). Megatrends digitalization. Report from the FGI study, http://www.kadra.org.pl/wp-content/uploads/2019/06/Cyfryzacja-raport-FGI.pdf.

7. Piotrowska, J., Siekiera, A., Sznajder, A. (2016). Jak realizować zasadę równości szans kobiet $i$ mężczyzn $w$ projektach finansowanych z funduszy europejskich 2014-2020. Warszawa: MR.

8. Strategia rozwoju społeczeństwa informacyjnego województwa ślaskiego 2020+ (2016). Katowice: Śląskie Centrum Społeczeństwa Informacyjnego.

9. Założenia do strategii AI w Polsce. Plan działania Ministerstwa Cyfryzacji (2018). Warszawa: MC. 